\title{
Ações da Terapia Ocupacional para a prevenção da violência com adolescentes: relato de pesquisa
}

\author{
Occupational Therapy actions in violence \\ prevention among youth: research report
}

\author{
Carolina Côrtes ${ }^{1}$, Daniela Tavares Gontijo ${ }^{2}$, Heliana Castro Alves ${ }^{3}$
}

CÔRTES, C.; GONTIJO, D. T.; ALVES, H. C. Ações da Terapia Ocupacional para a prevenção da violência com adolescentes: relato de pesquisa. Rev. Ter. Ocup. Univ. São Paulo, v. 22, n. 3 p. 208-215, set./dez. 2011.

\begin{abstract}
RESUMO: A violência constitui um fenômeno sócio-histórico dinâmico e complexo marcado por diversidades culturais e sociais, que causa impacto negativo na qualidade de vida da população. $\mathrm{O}$ artigo objetiva descrever e analisar a intervenção terapêutica ocupacional na prevenção da violência com adolescentes e verificar o potencial dos recursos na promoção de estratégias de enfrentamento ao fenômeno. A coleta de dados estruturou-se em registro em diário de campo e grupo focal. Utilizouse a análise de conteúdo, elaborando-se as categorias temáticas: atividades como expressão; como forma de elaboração de estratégias de enfrentamento à violência e Visão do grupo sobre as ações da Terapia Ocupacional. Conclui-se que as atividades estimularam os adolescentes a refletirem sobre a dinâmica da violência, elaborando estratégias de enfrentamento.
\end{abstract}

DESCRITORES: Terapia ocupacional; Violência; Prevenção primária.

- Acadêmica do curso de Terapia Ocupacional da Universidade Federal do Triângulo Mineiro - UFTM- carolcortes.to@hotmail.com

2. Docente Adjunta do Curso de Terapia Ocupacional da Universidade Federal do Triângulo Mineiro; doutora em Ciências da Saúde e pesquisadora do Núcleo de Estudos e Pesquisa em Vulnerabilidade e Saúde na Infância e Adolescência (NEPVIAS) do curso de Terapia Ocupacional UFTM-dtgontijo@gmail.com

3. Docente do Curso de Terapia Ocupacional da Universidade Federal do Triângulo Mineiro; mestre em Educação Especial pelo PPGEE da UFSCar e pesquisadora do Núcleo e Pesquisas em Vulnerabilidade e Saúde na Infância e Adolescência do curso de Terapia Ocupacional UFTM.

Endereço para correspondência:Rua Cipotânea, 51. Cidade Universitária 05360-000 - São Paulo, SP, Brasil. 


\section{INTRODUÇÃO}

violência constitui um fenômeno sócio-
histórico complexo e dinâmico marcado
pela diversidade cultural e pelos diferentes valores morais e éticos, que causa impacto sobre a qualidade de vida.

$\mathrm{Na}$ contemporaneidade, a violência atua como protagonista midiática, passando despercebida por sua extensa banalização. Sua "fama" estabelece uma rede de relações constituídas por indivíduos que perpetuam sua dimensão e relevância, constituindo um grave problema social por sua abrangência e magnitude (SILVA, 2007). Para Waiselfisz (2004, p.15), “o contínuo incremento da violência cotidiana configura-se como aspecto representativo e problemático da atual organização da vida social, manifestando-se nas várias esferas da vida societária”.

De acordo com Lisboa et al. (2009) a agressividade entre adolescentes e jovens, e, particularmente, a violência no contexto escolar, é um problema central discutido pela mídia, autoridades e pesquisadores. Tal fenômeno, conhecido por bullying, ocorre quando um estudante é exposto sistematicamente a diversos atos agressivos, sem motivação aparente, mas de forma intencional possuindo pouco ou quase nenhum recurso para evitar ou defender-se do ataque (LISBOA et al., 2009). O fenômeno bullying pode ainda provocar consequências nos aspectos psico-afetivos, comportamentais e sociais desse sujeito, prescindindo a intervenção de profissionais de diferentes áreas para a sua prevenção.

O terapeuta ocupacional (T.O.) se apresenta como um profissional qualificado para a demanda relacionada à violência, visto que objetiva o envolvimento do individuo na ocupação por meio do suporte à sua participação em diversos contextos - cultural, físico, social, pessoal, espiritual, e temporal.

A prática da Terapia Ocupacional (T.O.) no campo social fundou-se no conceito de cidadania e se organiza a partir do princípio da universalidade dos direitos sociais. Nesta esfera de ações, a T.O. foca na atenção nas demandas das pessoas excluídas do acesso aos bens culturais e sociais, e expostas à vulnerabilidade social, estimulando o processo de conscientização de cada ator social (GALHEIGO, 2003, p 32.).

Estes objetivos podem ser garantidos por meio da realização de atividades significativas que possibilitem a participação do indivíduo em suas diversas áreas de ocupação e desempenho (AOTA, 2008). As atividades que promovem a ação e o fazer podem ser meios para manifestação da singularidade do indivíduo, percepção, e compreensão dos fatos e fenômenos sociais cotidianos, visando o desenvolvimento de um pensamento reflexivo e ativo dos adolescentes.

Segundo Silva (2007) os contextos familiar e escolar são legitimados, cientificamente e socialmente, como espaços privilegiados das ações preventivas das problemáticas associadas aos adolescentes e jovens. Considerando a necessidade de proposições e desenvolvimento de estudos que enfoquem as estratégias para a prevenção da violência, a T.O. deve conduzir sua ação através do reconhecimento e compreensão do cotidiano e da história ocupacional dos adolescentes. De acordo com Galheigo (2003), é dessa maneira que o profissional poderá auxiliar o sujeito e a coletividade a reconhecerem e compreenderem os conflitos cotidianos, ressignificando seu fazer e pensar, fortalecendo a trama social, e, finalmente, viabilizando uma melhor eficácia das redes de apoio.

Percebe-se a necessidade de instrumentos que promovam a postura ativa dos adolescentes nos processos de fortalecimento das redes sociais de suporte, favorecendo a implantação e o desenvolvimento de ações efetivas na promoção da qualidade de vida. Como estratégia de enfrentamento às situações de violência na juventude, os T.Os. podem atuar a partir de grupos de discussões e atividades, promovendo a reflexão coletiva.

Os objetivos deste estudo são: descrever e analisar uma metodologia de intervenção terapêutica ocupacional para prevenção de violência na juventude e avaliar o impacto das atividades e recursos utilizados sobre a compreensão do fenômeno e na elaboração de estratégias de enfrentamento a violência.

\section{METODOLOGIA}

Trata-se de um estudo de caso, referido a uma análise detalhada de um grupo buscando explicar a dinâmica de um problema (MINAYO, 2008).

A pesquisa ocorreu em uma escola municipal de uma cidade do interior de Minas Gerais, tendo sido aprovada no CEP da Universidade Federal do Triângulo Mineiro sob o número 1399. A coleta de dados ocorreu em março de 2010. A amostra contou em média com cinco alunos com idade entre 12 e 14 anos. Foram realizados oito encontros de 2,5h cada um, duas vezes na semana durante um mês. O grupo era realizado no contra-turno do período escolar.

Os dados foram coletados a partir de entrevistas e de um grupo que desenvolveu atividades expressivas e jogos. Foi adotada a abordagem de Paulo Freire que enfatiza a necessidade do respeito ao conhecimento do educando, a partir da valorização de suas vivências, 
pensamentos e ideais, criando assim possibilidades para a produção e/ou construção ativa do conhecimento de mundo (FREIRE, 1996). Utilizou-se como instrumento de observação direta um roteiro e o diário de campo.

Após o grupo de atividades realizou-se um grupo focal, gravado em meio digital, objetivando avaliar as atividades enquanto recurso para a promoção de discussões sobre o fenômeno da violência, e obter uma reflexão dos adolescentes sobre as atividades e percepção quanto às ações da T.O.

A análise de dados foi desenvolvida a partir da técnica de análise do conteúdo proposta (MINAYO, 2008).

\section{RESULTADOS E DISCUSSÕES}

Foram utilizados recursos audiovisuais, atividades estruturadas e expressivas que tiveram por finalidade alcançar o universo do público estudado e promover a reflexão e elaboração de estratégias de enfrentamento à violência. A partir de um repertório inicial de atividades, os encontros, assim como os recursos, só foram definidos de acordo com as demandas e dinâmicas observadas no decorrer do processo (Tabela 1).

Tabela 1 - Atividades desenvolvidas

\begin{tabular}{|c|c|c|}
\hline Atividades Estruturadas & Atividades Expressivas & Recursos Audio Visuais \\
\hline $\begin{array}{l}\text { Jogo concordo/discordo: } \\
\text { Promover a expressão das opiniões dos adolescentes } \\
\text { sobre violência. }\end{array}$ & $\begin{array}{l}\text { Role-play: situações cotidianas e inversão de } \\
\text { papéis: vítima-agressor. }\end{array}$ & $\begin{array}{l}\text { Recurso Musical: "Desculpa mãe”- } \\
\text { Faccção Central. }\end{array}$ \\
\hline $\begin{array}{l}\text { Jogo do Tabuleiro Gigante: } \\
\text { Adolescentes representavam os “peões” do jogo. } \\
\text { Estimular a discussão, a reflexão, e a internalização } \\
\text { dos conceitos; resoluções de casos relacionados à } \\
\text { violência. }\end{array}$ & $\begin{array}{l}\text { Teatro Fórum (técnica de Augusto Boal): } \\
\text { Proporcionar uma experiência cênica coletiva } \\
\text { estimulando a reflexão sobre a resolução de } \\
\text { conflitos. }\end{array}$ & $\begin{array}{l}\text { Recurso áudio visual: } \\
\text { Edição de cenas de diversos filmes } \\
\text { expressando tipos de violências. }\end{array}$ \\
\hline $\begin{array}{l}\text { Entrevistas com outros alunos da escola e família } \\
\text { acerca da compreensão do fenômeno Buyling, propos- } \\
\text { to pelos próprios participantes. }\end{array}$ & $\begin{array}{l}\text { Apresentação cênica de tele-jornal : promoção } \\
\text { de debates com alunos de séries anteriores. }\end{array}$ & $\begin{array}{l}\text { Recurso áudio visual: } \\
\text { Apresentação de um clipe sobre } \\
\text { bullying. }\end{array}$ \\
\hline
\end{tabular}

Atividades Expressivas Estruturadas

Cartaz: Pontos positivos e negativos da juventude;

Proporcionou expressão, reflexão e discussão sobre juventude e vulnerabilidade, seus aspectos positivos e negativos.

A partir da análise dos dados coletados, três categorias temáticas foram elaboradas: "Atividade como expressão", "Atividades como forma de elaboração de estratégias de enfrentamento à violência", e "Visão do grupo sobre as ações da Terapia Ocupacional".

A categoria “Atividade como expressão" descreve o potencial das atividades em despertar a expressão do aluno frente ao fenômeno e a dinâmica da violência vivenciada nos diversos contextos adolescentes. No núcleo de sentido Expressão da violência no contexto escolar, os participantes relataram que a violência nesse contexto ocorre entre diversos atores sociais presentes na escola, e descrevem a complexa dinâmica social em que estes se manifestam. Tais relatos confirmam que violência perpassa pelos diversos níveis de relações, podendo ter como ator tanto alunos como professores e funcionários, em seus diversos papéis, quer como protagonistas, quer como vitimas (MARRIEL et al., 2006).

Observou-se a influência das relações hierárquicas, que envolvem alunos, professores e diretoria, remetendo esses atores a situações de violência dentro da comunidade escolar. Esses indícios são concordantes com os achados da pesquisa realizada por Marriel et al. (2006) que afirma ser a instituição escolar e os educadores possíveis agentes de violência, diante da ignorância sobre os problemas dos alunos, o tratamento pejorativo, as agressões verbais e a exposição do aluno a situações humilhantes. A expressão sobre o relacionamento com os professores ocupou parte significativa da fala dos alunos, assim como o autoritarismo e o abuso de poder. Da mesma forma, Silva (2007) também verificou as estratégias do processo de inclusão e exclusão sociais reproduzidas pela escola. 
Os adolescentes durante as atividades expressaram algumas estratégias, já utilizadas, contra a violência pautadas em condutas punitivas, evidenciando a existência de um universo cultural que prevê correções por meio de castigos/ punições e legitimam o uso da violência em equipamentos sociais frequentados por adolescentes (LOPES et al., 2008). Silva (2007) enfatiza a concepção da escola como espaço público a ser democratizado pela ação cidadã. Neste sentido, a punição como estratégia para evitar a violência torna-se uma contradição, fugindo às compreensões e aplicações pedagógicas (SILVA, 2007).

Por meio das atividades os participantes expressaram aspectos da dinâmica da violência escolar que remetem a questões relacionadas às características próprias da faixa etária. Essa fase da vida representa o resultado do desenvolvimento que ocorre na puberdade e que leva a uma alteração do equilíbrio psíquico, favorecendo a vulnerabilidade da personalidade, expressa na intensificação da sexualidade e na modificação nos laços com a família. $\mathrm{O}$ afastamento da família e o comportamento de oposição às normas possibilitam a criação de novas relações sociais em busca da construção e da afirmação de uma identidade (ERIKSON, 1976 apud SILVA, 2009).

O bullying, citado com frequência nos discurso dos participantes, é facilitado pela própria vulnerabilidade do adolescente que favorece sua exposição a situações de violência, tanto como agressor quanto como vitima. A vítima de bullying pode ser identificada por possuir baixa autoestima e dificuldade para reagir a situações agressivas, não suportando a pressão a que é submetida. O bullying pode, pois, acarretar em prejuízos e sérias consequências sócioemocionais e educacionais, inclusive na evasão escolar (MARRIEL et al., 2006).

Dentre os aspectos relacionados à dinâmica da violência na escola, foi identificado que os adolescentes utilizam a violência física como "reação contra o bullying". Eles destacaram que brigam para se defenderem de ofensas, humilhações e da própria agressão física, defendendo que estratégias como diálogo ou ignorar as ações agressivas não são adaptativas no contexto escolar, em consideração à cultura da violência pré-existente neste espaço social.

"Não adiantava conversar com o menino (agressor), porque as pessoas iriam me chamar de covarde”.

Desta forma, a preocupação com a difusão de uma imagem negativa na escola, típica da adolescência, adicionada a pactuação social com a violência, gera uma dinâmica interacional caracterizada pela banalização dos atos agressivos e interfere, consequentemente, no processo de construção de estratégias que passam a se pautar em ações no sentido de perpetuar a própria violência, gerando, dessa forma, um ciclo vicioso. Assim, vítima e agressor se confundem na interação entre a estrutura social e subjetividades (LOPES et al., 2008, p. 68).

Em relação à dinâmica da violência na escola percebeu-se que a intimidação é comum sendo utilizada como forma do adolescente afirmar a sua existência social no ambiente escolar, pautando suas ações nas demonstrações de poder. Desta forma, o bullying pode ser um fator desencadeante de diversos tipos de violência, significando uma forma de afirmação de poder interpessoal por meio da agressão (LISBOA, 2009, p. 61).

A banalização da violência na escola é evidenciada pela fala: "Bullying é igual à disciplina de português, tem todo dia ", corroborando com Marriel et al. (2006) ao afirmar que esses tipos de violência são fatos corriqueiros e arraigados na prática educacional. Tais práticas de afirmação social nos remetem às características singulares da faixa etária: a necessidade de "domínio do território" também se apresenta como um fator desencadeante da violência, uma vez que sobrevive quem é o mais forte (MARRIEL, et al., 2006).

No segundo núcleo de sentido - atividade como expressão sobre violência na comunidade - os adolescentes identificam, relacionam e expressam a violência na comunidade a partir de suas vivências pessoais. Nas dramatizações representaram cenas cotidianas e expressaram o impacto da banalização da violência na comunidade em que vivem.

Os adolescentes expressaram episódios de violência relacionados ao consumo de bebidas alcoólicas e substâncias psicoativas, violência física, sexual, exploração de trabalho infantil e preconceito. Neste sentido, destacam o contexto cultural- que apóia o uso abusivo de força e poder como solução e/ou incentivo de conflitos, como um importante fator que favorece a violência. Segundo o modelo ecológico, a violência é o resultado de uma complexa interação de fatores individuais, de relacionamento, sociais, culturais e ambientais (BRASIL, 2002, p. 13).

Os alunos discorreram sobre a violência estrutural, principalmente ao discutirem as cenas dos filmes utilizados na intervenção, apontando o recurso audiovisual como multiplicador de reflexões e discussões. Os participantes identificaram como violência a pobreza, corrupção, miséria e falta de acesso da população a serviços públicos, concordando com a definição descrita por Schraiber et. al (2006) que define que a violência no e do espaço público, perpassa pelas desigualdades sociais.

No terceiro núcleo de sentido - atividade como expressão sobre violência doméstica existiram relatos 
sobre situações de violência doméstica: briga com os pais; "abuso de autoridade", violência física e psicológica e muitos relatos de negligência e maus tratos. Os participantes reportaram características de sociedade adultocêntrica, que fere o Estatuto da Criança e do Adolescente, que garante o direito destes atores sociais a não serem submetidos a qualquer forma de punição corporal, mediante a adoção de castigos moderados ou imoderados, sob a alegação de quaisquer propósitos, ainda que pedagógicos (BRASIL, 2002).

Ao discutir a violência doméstica, os adolescentes relataram cenas relacionadas ao uso de substâncias psicoativas e envolvimento com tráfico, também por motivos relacionados a conflitos típicos desta faixa etária.

A família representa o primeiro ambiente do qual a criança e o adolescente participam ativamente, sendo importante a reflexão sobre as práticas e relações desenvolvidas nesse contexto. Os participantes relataram que é bastante comum o uso de práticas parentais autoritárias envolvendo agressões físicas, demonstrando a banalização da violência também neste contexto. A punição física como uma prática disciplinar tem sido descrita na literatura como prejudicial ao desenvolvimento destes sujeitos (CECCONELLO et al., 2003, p. 44).

Os adolescentes também expressaram situações que envolveram relações parentais, em alusão à dinâmica da violência em diferentes esferas, a partir de um recorte sobre o gênero. Um dos participantes relatou que quando sofre algum tipo de violência física na escola é punido fisicamente pelo pai, o que não ocorre com as meninas. Observa-se que a família exige do menino um comportamento agressivo na escola face à violência, punindo-os frente à condição de vítimas que assumem, enquanto a passividade é aceita por parte do gênero feminino.

A partir do estímulo provocado por uma música, os adolescentes debateram a função da família de cuidado, a punição física e a negligência. Constatou-se, ademais, o aprendizado de novos termos relacionados ao tema, como o conceito de negligência, identificando-o a um tipo de violência.

A categoria - Atividades como forma de elaboração de estratégias de enfrentamento à violência identifica os recursos que promoveram a reflexão critica sobre estratégias de enfrentamento à violência nos diversos contextos, bem como as dificuldades dos adolescentes para pensar em soluções para conflitos violentos. Neste cenário, a participação social destes atores na comunidade escolar e a relação com a família a partir da promoção de diálogo, da ampliação do suporte social e da divulgação do fenômeno, também refletiram a elaboração de estratégias de prevenção e enfrentamento.

Durante a realização das dramatizações os alunos demonstraram dificuldades no processo de reflexãotransformação das situações de violência sugeridas por eles no jogo dramático. As encenações reproduziram as vivências dos alunos na escola e a tentativa, por vezes frustrada, de resolução das cenas expressou os conflitos emocionais dos adolescentes para lidar com a complexidade do fenômeno nesse contexto. Ao atuarem nas cenas de violência, reproduziram condutas e estratégias já utilizadas pela escola, apesar de criticá-las, demonstrando dificuldade em transformar a realidade vigente.

Takeiti e Galheigo (2005), também observam dificuldades na dramatização relacionadas à elaboração do diálogo e à organização da cena. Afirmam a atividade teatral como desafiadora para este público, por exigir desenvoltura e pelo fato da ficção se misturar com a realidade. Em uma das dramatizações realizadas, A. (que possui perfil de agressora no cotidiano escolar), dramatizou o papel de vítima, e foi possível perceber sua dificuldade emocional em representar o papel diante do conflito de se ver no lugar do outro. Esses dados são concordantes com Galheigo (2005, p. 130) que diz que a atividade de teatro permite a manifestação de conteúdos grupais em sua horizontalidade (o acontecer grupal) e verticalidade (a história pessoal).

Os adolescentes refletiram criticamente sobre os castigos utilizados na escola, como a suspensão e a falta de educação física, enfatizando que essas práticas não desestimulam a violência. Pode-se relacionar suspensão escolar ao bullying, pois, em ambas, há dinamização cíclica da violência. Aludiram também a inação da escola quando a violência extrapola seus muros, desprotegendo os adolescentes que são jurados de perseguição após o período de aulas.

Os participantes tomaram a iniciativa de realizar uma pesquisa sobre a compreensão do fenômeno bullying entre seus pares e elaboraram, em seguida, um tele-jornal para divulgar o conceito em outras turmas. Constataram que a maioria dos alunos, pais e professores conhecem o termo bullying, e já foram agressoras e/ou vitimas do fenômeno. $\mathrm{Na}$ dramatização para os seus pares, os adolescentes reproduziram assim, estratégias e recursos utilizados durante os encontros (Teatro-fórum), além de folhetos informativos, como meio de divulgação do fenômeno bullying e interação com toda comunidade escolar.

$\mathrm{Na}$ apresentação teatral, os adolescentes transpareceram segurança e apropriação do conhecimento sobre o fenômeno bullying e refletiram ativamente com os espectadores formas de enfrentamento da violência, 
tornando-se agentes de transformação na escola. O envolvimento dos alunos e espectadores com os recursos utilizados demonstrou a possibilidade de maior participação social dos sujeitos, assim como a sua valorização através de ações que proporcionam o protagonismo juvenil, em que são percebidos como os principais interventores de suas vidas (LOPES et al., 2008).

Os professores que assistiram à peça reconheceram durante o debate que a escola não está preparada para intervir junto a essa problemática. É necessário pontuar que os educadores são facilitadores do processo ensinoaprendizagem, possuindo imensurável relevância na prevenção da violência. No entanto, associa-se à densidade e abrangência da violência na atualidade e à ineficiência de modelos democráticos por parte da escola, o despreparo dos profissionais e a falta de uma rede de suporte que amplie as ações revogadas à escola (SILVA, 2007).

A partir de discussão de "casos" e atividades estruturadas o grupo elaborou novas estratégias de enfrentamento, como ações de apoio mútuo, refletindo sobre como ajudar um colega que está sendo vitima de bullying.

"A gente podia abrir um clubinho de pessoas que já sofreram bullying, ai um poderia ajudar o outro e vê que não é só ele que sofreu".

Tal estratégia valida a amizade e a organização social entre discentes, como fator de proteção na ampliação da rede social de suporte das possíveis vítimas no contexto escolar. Outra estratégia encontrada pelos adolescentes foi a de isolar socialmente o agressor e evitar o incentivo coletivo à briga, o que perpetua a cultura da violência neste contexto.

Os estudantes destacaram que antes das intervenções existia uma dificuldade em falar com suas famílias a respeito da violência no contexto escolar. Percebe-se que as atividades proporcionaram uma relação mais estreita com a família, instrumentalizando-os para o diálogo nessa esfera. Ressaltaram que seus pais não tinham conhecimento sobre o bullying e que a partir das discussões no grupo, puderam promover o diálogo e aproximação com suas famílias, permitindo que o conteúdo discutido transcendesse o espaço dos encontros. Esse impacto identifica que a aproximação dos adolescentes com suas famílias atuou como um fator para o fortalecimento de um dos principais elementos da rede de suporte social, favorecendo diretamente a elaboração de novas formas de enfrentamento frente à dinâmica da violência.

Percebe-se também que a partir das atividades e da conscientização sobre a violência na escola, os adolescentes compreendem a possibilidade de prevenção para gerações futuras:

"E a gente sabe que no futuro quando for ter nossos filhos, a gente vai ter que prestar bem atenção, por que já vamos saber o que é bullying, já vamos ficar prestando atenção se ta acontecendo bullying com eles".

A categoria "Visão do grupo sobre as ações da T.O.”, reporta à percepção dos adolescentes sobre as atividades desenvolvidas, e suas impressões quanto à postura, papel e habilidades do terapeuta, diferenciando-o de outros profissionais. O núcleo de sentido - Postura do terapeuta: aprender e ensinar, discorre sobre as percepções dos estudantes acerca das intervenções da T.O. Os participantes destacaram que as intervenções possibilitaram uma relação horizontal em que se sentiram valorizados pelo conhecimento de mundo que possuem, ao constatar que poderiam expor suas idéias e as vivências do seu universo sobre o tema em pauta, sem repressões, em uma troca mútua de conhecimento e aprendizado.

\footnotetext{
“(...) teve atividade que a gente aprendeu, e teve atividade que a gente ensinou”
}

Essa percepção dos adolescentes sobre o espaço construído relaciona-se à abordagem de Paulo Freire que concebe o educando como um sujeito sócio-histórico, respeitando-o na sua visão e conhecimento de mundo, numa troca dialética de saberes (FREIRE, 1996).

No núcleo de sentido Percepção da T.O em ação, os adolescentes compreenderam as ações e o papel da T.O., diferenciando suas formas de intervir em relação a outros profissionais. Caracterizaram a profissão principalmente pelo uso de atividades que envolvem a ação e o fazer, agindo como canais de comunicação com o universo juvenil (TAKEITI; GALHEIGO, 2005). Galheigo (2005) afirma que $o$ adolescente possui seu pensamento abstrato ainda em construção, o que favorece a linguagem da ação como uma forma de comunicação, e é através do fazer que o terapeuta identifica essa peculiaridade, e traduz a expressão.

Os adolescentes discutiram que a ação da T.O. foi significativa, pois os recursos utilizados os envolveram através de ações muito próximas ao seu "universo", percebendo o T.O., portanto como um profissional qualificado para atuar dentro da escola.

O núcleo de sentido Avaliação das atividades constitui a percepção do aluno acerca da utilização das atividades, concluindo que as ações que tiveram menor 
envolvimento e satisfação foram as que se aproximaram aos métodos utilizados no contexto escolar, como construção de cartaz.

Observou-se a potencialidade dos recursos audiovisuais para a identificação das características do agressor e da vitima, permitindo que os participantes relacionassem diretamente os papéis que eles atuam na realidade escolar, assim como os papéis exercidos por outros personagens neste ambiente. Este dado se assemelha ao de Lopes et al. (2008), ao afirmarem que esses recursos são instrumentos de diálogo com o universo juvenil, pois a imagem é um recurso catalisador que possibilita ao público perceber a si mesmo.

As atividades foram pontuadas como estratégias significativas, pois, se aproximam da realidade dos alunos, envolvendo-os ativamente. Mesmo com as dificuldades discutidas na categoria anterior, os participantes ratificam o teatro como recurso significativo para a reflexão e elaboração de enfrentamento a violência. "Ah eu gostei, deu pra aprender com o teatro, ficou muito mais fácil, porque às vezes um texto é difícil de ler, e é melhor entender pelo teatro...".

Os recursos promoveram novos conhecimentos sobre o fenômeno da violência, revelando que as atividades propiciaram aprendizado. As atividades expressivas, portanto, estimularam a participação ativa do público, permitindo a experimentação de possibilidades de aprendizado, diferentes dos modelos educacionais hierarquizados e disciplinadores que direcionam as práticas pedagógicas nas escolas (LOPES et al., 2008).

A experiência, portanto, confirma a relevância das ações do T.O. para a reflexão e elaboração de estratégias de enfrentamento ao fenômeno da violência, mostrando um profissional que consegue se inserir na cultura e realizar ações significativas a partir de uma relação dialógica, democrática e aberta com os adolescentes.

\section{CONCLUSÕES}

Diante o número de participantes e tempo de realização, este estudo não permite generalizações, tratandose de um grupo circunscrito à determinada realidade. No entanto, seus resultados podem subsidiar reflexões e práticas que possibilitam a construção de saberes sobre o tema.

Defende-se a compreensão sociológica da faixa etária circunscrita à adolescência ( $10 \mathrm{a} 14$ anos), entendendo estes sujeitos como cidadãos inseridos no contexto social, permeáveis, portanto, aos valores e conflitos sociais evidenciados na sociedade por fenômenos como a violência, e que interferem, não apenas na estruturação da personalidade, mas na forma como irão desempenhar, futuramente, seus papéis sociais.

As intervenções permitem afirmar que as atividades possibilitaram a reflexão sobre situações cotidianas, além da identificação dos tipos de violência que vivenciam. A reflexão sobre a violência é o primeiro passo para a elaboração de estratégias de enfrentamento e prevenção ao fenômeno nos diversos contextos, sendo fundamental a conscientização destes atores sociais. Diante a banalização da violência, identificar suas formas e alguns conceitos sobre o tema instrumentaliza o adolescente a lidar com situações cotidianas, possibilitando uma busca ativa pela qualidade de vida nas relações interpessoais.

As atividades mostraram-se significativas, contribuindo para a construção de redes de suporte e reformulação de estratégias de enfrentamento à violência no contexto escolar. Assim, os recursos que proporcionaram maior envolvimento foram as atividades expressivas, norteadas predominantemente por ação e movimento. Estas permitiram atuar sob a perspectiva do protagonismo juvenil e a livre expressão de idéias, possibilitando a reflexão, discussão, e criação de soluções para o problema da violência.

Ressalta-se ainda a importância do comprometimento e estreitamento das relações entre pais/ comunidade e escola, para que possam se conscientizar da problemática, atuando como aliados na orientação de adolescentes e jovens junto à prevenção da violência. Conclui-se ser fundamental a divulgação do fenômeno para um impacto multidimensional, envolvendo diferentes setores sociais possibilitando a elaboração coletiva de soluções para a problemática.

A escola deve, portanto, discutir com a comunidade temas socialmente relevantes que interferem no desenvolvimento dos alunos, como a violência e sua prevenção. Entretanto, verificou-se a dificuldade da escola em realizar ações preventivas, assumindo, no geral ações, punitivas e demonstrando indiferença quando a violência se manifesta na comunidade, fora dos seus muros. É importante que a escola se comprometa com a competência social dos alunos, vislumbrando seu contexto comunitário e também na consideração do fortalecimento do vínculo com o professor para a prevenção do fenômeno.

Para a construção de programas de prevenção da violência na juventude, percebe-se a importância de uma profunda compreensão da dinâmica da violência considerando as características peculiares da faixa etária e contexto cultural que os tornam particularmente vulneráveis a este fenômeno.

Verifica-se que a parceria entre a T.O. e comunidade 
CÔRTES et al. Ações da Terapia Ocupacional. Rev. Ter. Ocup. Univ. São Paulo, v. 22, n. 3 p. 208-215, set./dez. 2011.

escolar pode proporcionar a construção de programas e estratégias que objetivem uma cultura pela paz, possibilitando a realização de ações focadas na reflexão crítica do adolescente sobre sua realidade tendo, para tanto o amparo e sustentação de uma relação pautada na construção conjunta de saberes que visem a transformação social.

CÔRTES, C.; GONTIJO, D. T.; ALVES, H. C. Occupational Therapy actions in violence prevention among youth: research report. Rev. Ter. Ocup. Univ. São Paulo, v. 22, n. 3 p. 208-215, set./dez. 2011

\begin{abstract}
Violence serves as a media player, going unnoticed by his extensive trivialization, which is a socio-historical phenomenon marked by complex dynamic cultural and social diversities. The present article aims to describe and analyze the occupational therapeutic intervention in the violence prevention among youth and check the potential of Occupational Therapy resources in the promotion of strategies to confront the violence phenomenon. The data was collected in field diary and focal group. A content analysis was used, and the following thematic categories were developed: activities as expression; as means of strategies' elaboration to confront violence and points of view about Occupational Therapy actions. It has been concluded that the activities stimulates the youth to reflect upon the dynamics of violence, creating strategies to cope with it.
\end{abstract}

KEY WORDS: Occupational Therapy; Violence; Primary prevention.

\title{
REFERÊNCIAS
}

BRASIL. Secretaria de Estado dos Direitos Humanos Departamento da Criança e do Adolescente. Estatuto da Criança e do Adolescente Lei n.8.069, de 13 de julho de 1990. Brasília, 2002.

BRASIL. SIM - Sistema de informações sobre mortalidade. Brasília, 2005. Disponível em: <http://tabnet.datasus.gov.br/cgi/ idb2007/matriz.htm\#mort>. Acesso em: 14 maio 2009.

CECCONELLO, M. A.; et. al. Práticas educativas, estilos parentais e abuso físico no contexto familiar. Psicol. Estudo, Maringá, v. 8, p. 54-45, 2003.

FREIRE, P. Pedagogia da autonomia. Editora EGA, 1996. Disponível em: <http://www.letras.ufmg.br/espanhol/ pdf $\% 5$ Cpedagogia_da_autonomia_paulofreire.pdf $>$. Acesso em: 2 jun. 2009

GALHEIGO, S. M. O. O social: idas e vindas de um campo de ação em terapia ocupacional. In: GALHEIGO, S. M. (Org). Terapia ocupacional. São Paulo: Papirus, 2003.

GALHEIGO, S. M. Quatro grupos, vivências, fragmentos de histórias: jovens em tempos de violência. In: MARCHESINI, E. M.; PÁDUA, L. Casos, memórias e vivências. Campinas: Papirus, 2005. p. 116-144.

LISBOA, C.; BRAGA, L. L.; EBERT, G. O fenômeno bullying ou vitimização entre pares na atualidade: definições, formas de manifestação e possibilidades de intervenção. Contextos Clínicos, São Leopoldo, v. 2, n. 1, p. 71-59, jan/jun, 2009.
LOPES, R.; et al. Juventude pobre, violência e cidadania. Saúde Sociedade, São Paulo, v. 17, n. 3, p. 63-76, 2008.

MARRIEL, C. M.; et al. Violência escolar e auto-estima de adolescentes. Cad. Pesqui., São Paulo, v. 136, n. 127, p. 35-50, jan./abr. 2006.

MINAYO, M. C. S.; DESLANDES, S. F.; GOMES, R. Pesquisa social, teoria, método e criatividade. Petrópolis: Vozes, 2008.

SCHRAIBER, B. L.; et al. Violência e saúde: estudos científicos recentes. Rev Saúde Pública, v. 40, n esp., p. 112-120, 2006.

SILVA, C. R. Políticas públicas, educação, juventude e violência da escola: quais as dinâmicas entre os diversos atores envolvidos? São Carlos, 2007. Dissertação de Mestrado - Educação. São Carlos: UFSCar, 2007. p.184.

SILVA, C. R.; LOPES, R. E. Adolescência e juventude: entre conceitos e políticas públicas. Cad. Ter. Ocup. UFSCar, São Carlos, v. 17, n. 2, p.106-187, jul./dez. 2009.

TAKEITI, B. A.; GALHEIGO, S. M. Adolescência, reciprocidade e ação territorial: o teatro como estratégia de ação na Terapia Ocupacional. In: CONGRESSO BRASILEIRO DE TERAPIA OCUPACIONAL, 9., Recife; 2005. Anais. Recife, 2005.

WAISELFISZ, J. J. (Coord.). Relatório de desenvolvimento juvenil 2007 - Rede de Informação Tecnológica Latino Americana RITLA. Brasília, DF: MCT, 2007. 